\title{
A milestone for mental health in South Africa
}

The importance of mental health globally was recognised as far back as 1946 when the World Health Organization defined health as: "a state of complete physical, mental and social well-being and not merely the absence of disease or infirmity". " This definition is as pertinent now as it was in 1946 and the dictum that "there can be no health without mental health" is even now gaining momentum internationally. ${ }^{2}$ The burden of mental illness is felt not only through the primary presentation of mental disorders, but also through its high co-morbidity with other illnesses. ${ }^{3}$ Evidence has also shown that poor mental health is not just an individual or personal issue but one that both shapes development and is shaped by social and economic forces. ${ }^{4}$ Mental health is fundamental to the achievement of a number of the Millennium Development Goals including eradicating poverty, reducing child mortality, improving maternal health, achieving universal primary education and combating HIV and AIDS, malaria and other diseases. ${ }^{5}$

Since 1994 the South African government has demonstrated commitment towards improving mental health services, initially through the bold principles adopted for mental health and substance abuse in the White Paper for the Transformation of Health Systems in South Africa (1997) and subsequently through the Mental Health Care Act No. 17 of 2002. This Act is human rights orientated and promotes community based care over institutional treatment where possible. It also emphasizes integration of mental health with general health care services.

It is disturbing though that despite this legislation which is regarded as one of the most progressive mental health legislations in the world, persons with mental disorders are often still stigmatized and discriminated against. The Department has taken a number of steps to implement the key provisions of the Act, but we acknowledge that many challenges are still being encountered. Among these is limited access to mental health services, slow progress in integrating mental health into general health care and continued overreliance on custodial care. ${ }^{6,7}$ Moreover even though we know now that most upstream determinants of mental health and ill-health lie beyond the reach of the health sector and require inter-sectoral collaboration, this collaboration still requires strengthening. ${ }^{6}$

In April 2012 the Department Health convened a Summit on mental health to bring all major role-players together to assess the current situation and to agree on future directions. The Summit represented a significant milestone for mental health as it provided the platform for government to interact with stakeholders and objectively review both the quality and quantity of mental health services that we currently provide, identify the key challenges in the mental health care system, provide information on and share best practices that have emerged since 1994 and agree on key interventions that must be prioritized and implemented as we reorganize and strengthen the health system. The conclusion of the summit and the declaration, The Ekurhuleni Declaration on Mental Health- April 2012, agreed by participants (and published in this edition of the Journal) will, I am sure, assist us as a country in improving our mental health delivery system.

Various papers that were presented at the summit by researchers, academics, mental health care users and clinicians and experts in infrastructure development, covering a wide range of topics in mental health, are included in this special edition of the Journal. It is my belief that this wealth of knowledge and the declaration will not only benefit South Africa but other countries in and outside Africa in moving to more equitable and just mental health services and promotion of good mental health.

Dr G Ramokgopa

Deputy Minister of Health: Republic of South Africa

\section{References}

1. World Health Organization. Preamble to the Constitution of the World Health Organization as adopted by the International Health Conference, New York, 19-22 June, 1946 and signed on 22 July 1946 by the representatives of 61 States (Official Records of the World Health Organization, no. 2, p. 100, 1946) and entered into force on 7 April 1948.

2. World Health Organization. Promoting mental health: Concepts, emerging evidence, practice. A report of the World Health Organisation, Department of Mental Health and Substance Abuse in collaboration with the Victorian Health Promotion Foundation and the University of Melbourne. Geneva, Switzerland: World Health Organization.2005.

3. Prince M, Patel V, Saxena S, Maj M, Maselko J, Phillips MR, et al. No health without mental health. Lancet 2007; 370 (9590):859-877.

4. World Health Organization. Mental health: strengthening our response. Fact sheet $N^{\circ} 220$ September 2010; http://www.who.int/mediacentre/factsheets/fs220/en/

5. Miranda JJ, Patel V. Achieving the Millennium Development Goals: Does mental health play a role? PLoS Medicine October 2005; vol 2, no.10, e291 [online] Available www.plosmedicine.org

6. Lund C, Kleintjes S, Campbell-Hall V, Mjadu S, Petersen I, Bhana A, et al. Mental health policy development and implementation in South Africa: a situation analysis Phase 1. Country Report. Cape Town: The Mental Health and Poverty Project. 2008.

7. Petersen I, Lund C. Mental health services in South Africa in the past decade (2000-2010). One step forward, one step back. South African Medical Journal 2011; 101 (10): 751-757. 